\title{
Biobehavioral research on nicotine use in women
}

\author{
CYNTHIA S. POMERLEAU, OVIDE F. POMERLEAU \& ANNE \\ WEINSTEIN GARCIA
}

\author{
Behavioral Medicine Program, University of Michigan Department of Psychiatry, Riverview \\ Medical Building, 900 Wall Street, Ann Arbor, Michigan 48105, USA
}

\begin{abstract}
More American women are taking up smoking than men and fewer are quitting; if current trends continue, rates for women will surpass those for men by the mid-1990's. But ironically, much of what is known about the biobehavioural aspects of smoking is based on research using male subjects. The present paper reviews evidence suggesting that: (1) women may differ from men with regard to nicotine intake and/or effects; (2) nicotine intake and effects may be influenced by menstrual cycle phase; (3) oral contraceptive use and estrogen replacement therapy may affect intake and effects of nicotine; (4) the effects of chronic nicotine use on female reproductive endocrinology may have implications for the reinforcement of smoking; and (5) pharmacological agents used to treat smoking may have different effects in women than in men. Guidelines and suggestions are presented by future biobehavioural research in women, including standardization of assessment procedures, attention to the use of appropriate controls, and use of pharmacological probes.
\end{abstract}

\section{Introduction}

In the wake of Surgeon General Luther Terry's landmark report (USPHS, 1964) documenting the negative health effects of cigarette smoking, the prevalence in American men declined much more steeply (from $50.2 \%$ in 1965 to $31.7 \%$ in 1987) than in women (from $31.9 \%$ to $26.8 \%$; USDHHS, 1989 ). If current trends continue, smoking rates for women will surpass those for men by the mid-1990's (USDHHS, 1989). Initiation rates have dropped much faster among males than among females (USDHHS, 1989). Women quit with greater difficulty (or perhaps are treated less successsfully, using methods less appropriate to them; e.g. Blake et al., 1989; USDHHS, 1980) and are more likely to relapse than their male counterparts (Gritz, 1980).

As major users of the health care system, women have probably been adequately studied in treatment

Please address proofs and correspondence to Cynthia S. Pomerleau, $\mathrm{PhD}$, at the above address. trials (e.g. Hooper, 1990). But ironically, much of the basic behavioural and biological research that underlies the development of these treatment strategies has been carried out in males. Perhaps there will turn out to be more similarities than differences between men and women with respect to smoking patterns and effects of nicotine; but such a conclusion must be demonstrated, not assumed. If we wish to know about smoking in women, we must study women directly. The remainder of this paper will focus on questions that will need to be addressed, reviewing briefly what is known and discussing the kind of research required to fill the gaps in our knowledge.

Women may differ from men with regard to nicotine intake and/or effects

A certain amount of evidence has been amassed for sexual dimorphism in the effects of nicotine (Grunberg et al., in press). Clearance of nicotine corrected 
for body weight has been found to be significantly higher in men than in women (Benowitz \& Jacob, 1984); it has also been reported that women smoke fewer cigarettes than men but achieve comparable blood nicotine levels. Both these findings suggest that the effects of a given dose of nicotine may be more pronounced, if not qualitatively different, in women than in men. In keeping with this inference, Grunberg et al. (1986) have found that female rats are more sensitive than males to the effects of nicotine on body weight and feeding during and after drug administration. Other investigators have found male-female differences in motives for smoking (Russell et al., 1974) and in the kind of situations in which smoking is likely to occur (e.g. Ikard \& Tomkins, 1973). Although smoking rates have been linked to environmental stressors in both genders (e.g. Linsky et al., 1986), higher rates of negative-affect smoking in women may suggest that they respond differentially to stress or have fewer available instrumental responses for coping with stress. Alternatively, it has been proposed that nicotine is excreted faster when urinary $\mathrm{pH}$ is low, as occurs under stress (Schachter, 1978), and that changes in urinary $\mathrm{pH}$ produce greater excretion of nicotine in women than in men (e.g. Beckett $e t$ al., 1971). And although the literature is equivocal, evidence has been adduced to support the hypothesis that women, who have been shown in research on cognitive styles to be more responsive to external stimuli, may find the distraction-filtering effects of nicotine more useful than do men (see Biener, 1987). Interestingly, women smokers trying to quit are more likely to describe themselves as 'addicted' than are their male counterparts (Eiser \& Van Der Pligt, 1986).

\section{Nicotine intake and smoking behaviour may be affected by menstrual cycle phase.}

Investigation is needed of the possibility that the more than 200 physical, psychological, and behavioural changes associated with the ovarian cycle (Magos, 1988) have a systematic impact upon smoking behaviour in some or all regularly cycling women smokers. When we ask whether what is known about male subjects can be extrapolated to women, we must add 'to women when?'. A woman studied at one point in her menstrual cycle may perform differently at another, for reasons unrelated, or related in some complicated way, to the experimental manipulation.
The idea that drug use may fluctuate over the menstrual cycle, perhaps peaking at the premenstrual phase, has considerable face validity; but despite attempts to demonstrate such a phenomenon for several psychoactive substances, including caffeine, alcohol and marijuana, the only compelling evidence advanced to date has been in the presence of premenstrual syndrome (PMS). On the other hand, other appetitive responses-notably craving for food and food intake-have been convincingly shown to increase during the premenstruum.

Though the literature on smoking across the menstrual cycle is scanty, there is in fact a small amount of direct evidence to suggest that smoking behaviour and withdrawal symptomatology do change in response to menstrual phase. Based on automated measures of smoking topography, Steinberg \& Cherek (1989) found that most subjects smoked more during menses than during the premenstrual phase or any other time. Mello et al. (1987), looking at cigarette smoking and alcohol self-administration in women, found that nearly three-quarters increased smoking, as measured by inter-cigarette interval, during the premenstruum. All women reported increased psychological discomfort during the premenstruum, but reports of physical discomfort were more marked in women who smoked less during the premenstruum. O'Hara et al. (1989), in a study of premenopausal smokers enrolled in a smoking cessation clinic, found that subjects who quit during the luteal phase showed significantly higher ratings of withdrawal symptoms. Highly significant correlations were found between withdrawal scores and symptoms of menstrual distress.

Because of design limitations and inconsistent definitions of phase, these studies raise as many questions as they answer. Although two of the three tend to suggest more smoking and more desire to smoke during the latter part of the cycle, it is difficult to specify precisely the phase associated with increased smoking or to relate these studies to one another. The third study, by contrast, showed the highest smoking level during the menses; because days 1-2 were not distinguished from the remainder of the menses, it is not clear how much smoking in response to dysmenorrhea (see below) might have contributed to this effect. The absence of biochemical verification of menstrual phase or measures of plasma nicotine may also bear on the findings. Thus, inferences of greater self-administration either during menses or the premenstruum remain unconfirmed. 


\section{Effects of nicotine may vary across the menstrual cycle}

There is also a certain amount of inferential support, based on the known effects of smoking, for the hypothesis that smoking varies across (and in response to) menstrual phase. Smoking has frequently been demonstrated to serve as a pharmacological 'coping response' that can cause small but reliable alterations in performance or affect (Pomerleau \& Pomerleau, 1984). Behaviours and subjective states influenced by smoking or nicotine administration include improvement of various kinds of performance, such as tasks requiring vigilance or motor skills; decreased preference for and consumption of sweet-tasting food; decreased overall food consumption in female (but not male) rats; alleviation of anxiety; and antinociception (see USDHHS, 1988). Glassman et al. (1988) reported that smokers are more likely to have a history of clinical depression and suggested that some may smoke as a way of self-medicating.

Interestingly, the behavioral and subjective states affected by smoking have been demonstrated to fluctuate systematically over the course of the menstrual cycle. Hampson \& Kimura (1988), for example, have shown that during the midluteal phase, women tend to perform better on motor coordination tasks and worse on perceptual-spatial tests than do the same women during menses. Thus, women may smoke differentially in response to different types of challenge in an attempt to compensate for hormonally-induced performance deficits.

Numerous investigators have reported greater food intake, body weight, and craving for food, sweet-tasting food, or chocolate in the luteal phase than in the follicular phase (e.g. Bowen \& Grunberg, 1990; Dalvit, 1981). Since nicotine causes shifts in preference for and consumption of sweet-tasting foods, it is plausible that nicotine's well-documented anorectic and weight-depressing effects may increase in reinforcing value at key points in the menstrual cycle, especially in weight-conscious women.

Negative affect has been shown to increase premenstrually, especially in women who experience mood fluctuations over the menstrual cycle. Schechter et al. (1989), for example, recently reported significant increases in ratings of negative mood and 'less sociable' during the late-luteal phase as compared with four other endocrinologicallydefined segments of the cycle. It is not unreasonable to suppose that smoking is likely to increase at times when anxiety or depressive states are most severe.
Finally, some though not all investigators (see Veith et al., 1984) have reported changes in pain sensitivity and tolerance over the menstrual cycle, generally reaching a nadir during the luteal or lateluteal phase (Hapidou \& De Catanzaro, 1988; Rao et al., 1987). Furthermore, Andersch \& Milsom (1982) found that compared with non-smokers, females who smoke have significantly less severe dysmenorrhea, suggesting the possibility that smoking may relieve menstrual cramps. Thus, smokers suffering from dysmenorrhea may seek relief by smoking more during the early menses.

Though mechanisms whereby smoking might interact with hormonal fluctuations remain to be elucidated, nicotine administration has been shown in rats and humans to stimulate the release of dopamine, norepinephrine, beta-endorphin, cortisol, ACTH, growth hormone, vasopressin, and other neuroregulatory substances (see Pomerleau \& Rosecrans, 1989), many of which are involved in the regulation of affect or psychomotor performance. Since these substances are also influenced by menstrual cyclicity (Speroff et al., 1989), it is possible that smoking can be 'used' to compensate for adverse affective, cognitive, or physiological changes associated with different phases of the menstrual cycle. Alternatively, or additionally, alterations in the distribution, metabolism, and excretion of nicotine could result in decreased blood levels of nicotine at predictable times during the cycle, thereby leading to compensatory smoking (Steinberg \& Cherek, 1989).

Oral contraceptive use and estrogen replacement therapy may affect intake and effects of nicotine

Given the large numbers of women smokers who use oral contraceptives, and the negative health implications of combining the two practices (Gritz, 1980), it is important to determine the effects of exogenous steroids on smoking behavior and the effects of nicotine.

The effects of chronic nicotine use on female reproductive endocrinology may have implications for the reinforcement of smoking

Smoking appears to have a direct effect upon the menstrual cycle. The prevalence of menstrual irregularities is higher in smokers than in nonsmokers (e.g. Brown et al., 1988). Moreover, current smokers have been reported to reach 
menopause an average of 1.74 years earlier than non-smokers (McKinlay et al., 1985), and to have an increased incidence of osteoporosis (Baron, 1984), both of which are associated with a state of relative estrogen deficiency (Michnovicz et al., 1986). Possibly the antiestrogenic effects of nicotine produce changes in likelihood of ovulation, of menstrual cramps, and of premenstrual symptomatology, which in turn could affect smoking behavior.

\section{Pharmacological agents used to treat smoking may affect women differentially}

A number of drugs (e.g. antidepressants, antipsychotics) are known or suspected to have genderspecific effects or side-effects (see Hamilton, 1986). Several drugs, including nicotine itself, clonidine, fluoxetine, and mecamylamine, have been tested: as possible aids in smoking cessation; these drugs may likewise have differential effects in women. Glassman et al. (1988), for example, found clonidine promoted smoking cessation in women but not men; Killen et al. (1990), on the other hand, found nicotine polacrilex to be more effective in men than in women. Gender-specific concerns or needs may also have an indirect influence on drug efficacy. Fluoxetine, a drug with appetite-suppressing effects, for example, may be more helpful to women, who exhibit greater concern than men about the weight-gain that generally accompanies nicotine discontinuation (Sorensen \& Pechacek, 1987).

\section{What is needed?}

The need to take into account menstrual status and phase, risk of pregnancy, and use of exogenous steroid hormones, at least until we rule out the possible contributing effects of these factors, clearly adds an extra layer of complexity to the use of women as research subjects. On the other hand, these natural or artificial hormonal manipulations also represent research opportunities, with the potential for serving as independent variables that could increase our understanding of the functional relationships among hormones, behavior, and the reinforcement of smoking.

In any event, if we are to accumulate information efficiently, there are a number of considerations that need to be addressed. For example, it would be desirable to standardize definitions and criteria for verification of menstrual status, questionnaires used to assess subjective responses and mood cycling, measures of nicotine dependence, etc. so that studies will be mutually interpretable. Careful thought must be given to the appropriate control for a given study, be it time-yoked male controls, preversus post-menopausal women, women with and without premenstrual symptomatology, repeated measures using women at different menstrual phases, smokers versus non-smokers, highly dependent versus less dependent smokers, etc. In addition, we need imaginative new approaches to experimental manipulation; possible strategies include controlled administration of steroid hormones, use of hormone blockers, and other pharmacological manipulations of neuroregulatory activity -e.g. cholinergic, adrenergic, and opioid agonists and antagonists. Finally, it is important to study women not just in contrast to men, or in the hopes of generalizing from men to women, but as a population subject to a range of individual differences that need to be studied in and of themselves.

\section{Acknowledgements}

Work on this paper was supported by University of Michigan Psychiatry Research Committee funding to the first and third authors and by National Cancer Institute grant CA 42730 to the second author.

\section{References}

ANDERSCH, B. \& MiLSOM, I. (1982) An epidemiologic study of young women with dysmenorrhea, American Goumal of Obstetrics and Gynecology, 144, pp. 655-660. BARON, J. A. (1984) Smoking and estrogen-related disease, American foumal of Epidemiology, 119, pp. 9-22.

BECKETT, A. H., GorRod, J. W. \& JeNnER, P. (1971) The effect of smoking on nicotine metabolism in vivo in man, Yourmal of Pharmacy and Pharmacology, 23, pp. 625-675.

Benowitz, N. L. \& Jacob, P. (1984) Daily intake of nicotine during cigarette smoking, Clinical Pharmacology and Therapeutics, 35, pp. 499-504.

BIENER, L. (1987) Gender differences in use of substances, in: R. C. BARNETT, L. BIENER \& G. K. BARUCH (Eds) Gender and Stress, pp. 330-349 (New York, The Free Press).

Blake, S. M., Klepp, K-I., Pechacek, T. F., Folsom, A. R., LUEPKER, R. V., JACOBS, D. R. \& MITTELMARK, M. B. (1989) Differences in smoking cessation strategies between men and women, Addictive Behaviors, 14, pp. 409-418.

BowEN, D. J. \& GRUNBeRG, N. E. (1990) Variations in food preference and consumption across the menstrual cycle, Physiology and Behavior, 47, pp. 287-291.

Brown, S., Vessey, M. \& STRATtON, I. (1988) The infuence of method of contraception and cigarette smoking on menstrual patterns, British Yournal of Obstetrics and Gynecology, 95, pp. 905-910.

DaLvit, S. P. (1981) The effect of the menstrual cycle on patterns of food intake, American gournal of Clinical Nutrition, 34, pp. 1811-1815.

EISER, J. E. \& VAN DER PLIGT, J. (1986) 'Sick' or 'hooked': 
smokers' perceptions of their addiction, Addictive Behaviors, 11, pp. 11-15.

Glassman, A. H., Steiner, F., Walsh, B. T., Raizman, P. S., Fleiss, J. L., COOPER, T. B. \& CoveY, L. S. (1988) Heavy smokers, smoking cessation, and clonidine, Y $A M A, 259$, pp. 2863-2866.

GRITZ, E. R. (1980) Problems related to the use of tobacco by women, in: O. J. KaLANT (Ed.) Alcohol and Drug Problems in Women, pp. 487-543 (New York, Plenum Press).

Grunberg, N. E., BowEN, D. J. \& WINDERs, S. E. (1986) Effects of nicotine on body weight and food consumption in female rats, Psychopharmacology, 90, pp. 101-105.

Grunberg, N. E., Winders, S. E. \& Wewers, M. E. (in press) Gender differences in tobacco use, Health Psychology.

Hamilton, J. A. (1986) An overview of the clinical rationale for advancing gender-related psychopharmacology and drug abuse research, in: B. A. RAY \& M. C. BRAUDE (Eds) Women and Drugs: a new era for research (NIDA Research Monograph 65, DHHS Publication No. [ADM]87-1447], pp. 14-20 (Rockville, MD, USDHHS)

HAMPSON, E. \& KIMURA, D. (1988) Reciprocal effects of hormonal fluctuations on human motor and perceptualspatial skills, Behavioral Neuroscience, 102, pp. 456-459.

Hapidou, E. G. \& De Catanzaro, D. (1988) Sensitivity to cold pressor pain in dysmenorrheic and non-dysmenorrheic women as a function of menstrual cycle phase, Pain, 34, pp. 277-283.

HOOPER, C. (1990) Some drug trials show gender bias, Gournal of NIH Research, 2, pp. 47-48.

IKARD, F. F. \& TOMkINS, S. (1973) The experience of affect as a determinant of smoking behavior: a series of validity studies, fournal of Abnormal Psychology, 81, pp. 172-181.

Killen, J. D., FortmanN, S. P., Newman, B. \& Varady, A. (1990) Evaluation of a treatment approach combining nicotine gum with self-guided behavioral treatments for smoking relapse prevention, Gournal of Consulting and Clinical Psychology, 58, pp. 85-92.

LiNSKY, A. S., ColbY, J. P. \& STRAus, M. A. (1986) Social streess, smoking behavior and mortality from cancer of the respiratory system: a macro social analysis (paper presented at the Second National Conference on Social Stress Research, University of New Hampshire, Durham, NH).

MaGos, A. L. (1988) Effects and analysis of the menstrual cycle, Goumal of Biomedical Engineering, 10, pp. 105-109.

MCKinlay, S. M., Bifano, N. L. \& McKinlay, J. B. (1985) Smoking and age at menopause in women, Annals of Internal Medicine, 103, pp. 350-356.

Mello, N. K., Mendelson, J. H. \& Palmieri, S. I. (1987) Cigarette smoking by women: interactions with alcohol use, Psychopharmacology, 93, pp. 8-15.

Michnovicz, J. J., Hershcope, R. J., Naganuma, M. D., Bradlow, H. L. \& Fishman, J. (1986) Increased 2hydroxylation of estradiol as a possible mechanism for the anti-estrogenic effect of cigarette smoking, NEfM, 21, pp. 1305-1309.

O'Hara, P., Portser, S. A. \& Anderson, B. P. (1989)
The influence of menstrual cycle changes on the tobacco withdrawal syndrome in women, Addictive Behaviors, 14 , pp. 595-600.

Pomerleau, O. F. \& Pomerleau, C. S. (1984) Neuroregulators and the reinforcement of smoking: towards a biobehavioral explanation, Neuroscience and Biobehavioral Reviezus, 8, pp. 503-513.

Pomerleau, O. F. \& Rosecrans, J. (1989) Neuroregulatory effects of nicotine, Psychoneuroendocrinology, 14, pp. 407-423.

RaO, S. S., Ranganekar, A. G. \& Salfi, A. O. (1987) Pain threshold in relation to sex hormones, Indian fournal of Physiology and Pharmacology, 31, pp. 250-254.

Russell, M. A. H., Peto, J. \& Patel, V. (1974) The classification of smoking by factorial structure of motives, foumal of the Royal Statistics Society, 37, pp. 313-346.

SCHACHTER, S. (1978) Pharmacological and psychological determinants of smoking, Annals of Internal Medicine, 88, pp. 104-114.

Schechter, D., Bachman, G. A., Vattukaitis, J., PhILLIPS, D. \& SAPERSTEIN, D. (1989) Perimenstrual symptoms: time course of symptom intensity in relation to endocrinologically-defined segments of the menstrual cycle, Psychosomatic Medicine, 51, pp. 173-194.

SORENSEN, G. \& PECHACEK, T. F. (1987) Attitudes toward smoking cessation among men and women, fournal of Behavioral Medicine, 10, pp. 129-137.

SPEROFF, L., GLASS, R. H. \& KaSE, N. G. (1989) Clinical Gynecologic Endocrinology and Infertility (Baltimore, MD, Williams \& Wilkins).

SteinberG, J. L. \& CheREK, D. R. (1989) Menstrual cycle and smoking behavior, Addictive Behaviors, 14, pp. 173-179.

US Department of Health and Human Services (1980) The health consequences of smoking for women. $A$ report of the Surgeon General (US Department of Health and Human Services, Public Health Service, Office of the Assistant Secretary for Health, Office on Smoking and Health, DHHS Publication No. HH5396, Washington, DC, US Government Printing Office).

US Department of Health and Human Services (1988) The Health Conseequences of Smoking: Nicotine Addiction. A Report of the Surgeon General, DHHS 888406.

US Department of Health and Human Services (1989) Reducing the health consequences of smoking: 25 years of progress. $A$ report of the Surgeon General (US Department of Health and Human Services, Public Health Service, Centers for Disease Control, Center for Chronic Disease Prevention and Health Promotion, Office on Smoking and Health, DHHS Publication No. (CDC) 89-8411, Washington, DC, US Government Printing Office).

US Public Health Service (USPHS) (1964) Smoking and health. A report of the Surgeon General (US Department of Health, Education, and Welfare, Public Health Service, Center for Disease Control, PHS Publication No. 1103, Washington, DC, US Government Printing Office).

Veith, J. L., Anderson, J., Slade, S. A., Thompson, P., Laugel, G. R. \& GeTzlaf, S. (1984) Plasma betaendorphin, pain thresholds and anxiety levels across the human menstrual cycle, Physiology $\mathfrak{F}$ Behavior, 32, pp. 31-34. 
This document is a scanned copy of a printed document. No warranty is given about the accuracy of the copy. Users should refer to the original published version of the material. 